\title{
Formulation, Characterization and In-vitro Evaluation of Cetrizine HCL Oral Disintegrating Tablets
}

\section{Harshita $P^{*}$, Phalguna $\mathbf{Y}^{1}$, Sandhya $\mathbf{R}^{2}$}

${ }^{1}$ Bharat Institute of Technology, Mangalpally(V), Ibrahimpatnam(M), Ranga Ready, Hyderabad, Telangana, India 2Bharat school of Pharmacy, Mangalpally(V), Ibrahimpatnam(M), Ranga Ready, Hyderabad, Telangana, India

\begin{abstract}
A B S T R A C T
The main objective of this work is to formulate and evaluate Cetirizine HCl MFDT's using different concentrations of superdisintegrants like croscarmellose sodium (CCS), sodium starch glycolate (SSG) and their combinations in different ratios. The in vitro disintegration time of Cetrizine $\mathrm{Hcl}$ prepared by direct compression method by super disintegrates were found to be in the range of 18 to $11 \mathrm{sec}$ fulfilling the official requirements. The bulk density and tapped bulk density for the entire formulation blend varied from $0.508 \mathrm{gm} / \mathrm{cc}$ to $0.5438 \mathrm{gm} / \mathrm{cc}$ and 0.5941 to 0.6408 respectively. The friability was found in all designed formulations in the range 0.42 to $0.74 \%$ to be well within the approved range $(<1 \%)$. The weight variation was found in all designed formulation in the range 97 to $102 \mathrm{mg}$. The wetting time were found to be in the range of 11 to $18 \mathrm{sec}$. Water absorption ratio for all the formulations found in the range 11 to $16 \%$.combination of sodium starch glycolate and cross carmellose sodium $(6 \%$ of $25 \%$-ssg\& $75 \% \mathrm{ccs}))$ promotes dissolution rate of drug release when compared to formulation of SSG \& CCS alone. It may be due to capillary and wicking mechanism of SSG \& CCS.
\end{abstract}

Keywords: Super disintegrates, Cetrizine hydrochloride, Sodium starch Glycolate, Crosscarmellose.

A R T I C L E I N F O: Received 15 June 2019; Review Completed 14 August 2019; Accepted 06 Sept. 2019; Available online 15 Oct. 2019
Cite this article as:
$\begin{aligned} & \text { Pasupulati H, Phalguna Y, Rudra S,Formulation, Characterization and In-vitro Evaluation of Cetrizine HCL Oral Disintegrating } \\ & \text { Tablets, Asian Journal of Pharmaceutical Research and Development. 2019; 7(5):19-25, } \\ & \text { DOI: http://dx.doi.org/10.22270/aiprd.v7i5.563 } \\ & \text { *Address for Correspondence: } \\ & \text { Haritha Pasupulati, Bharat Institute of Technology, Mangalpally(V), Ibrahimpatnam(M), Ranga Ready, } \\ & \text { Hyderabad, Telangana, India }\end{aligned}$

\section{INTRODUCTION}

$\mathrm{D}$ rug delivery systems (DDS) are a key device for growing markets/signs, broadening item life cycles and producing openings. DDS has made a significant contribution to global pharmaceutical sales through market segmentation, and are moving rapidly ${ }^{1}$. Orally disintegrating tablets (ODT) are oral strong dose frames that break down in the oral depression in simple swallow buildup. Orally disintegrating tablets are also known as "Mouth dissolving tablets", "Orodispersible tablets", "Melt- in-mouth Fast dissolving drug delivery, Rapimelts tablets, Porous tablets, Quick dissolving tablets" 2 etc. Recently ODT terminology has been approved by United States Pharmacopoeia, British Pharmacopoeia, and Centre for Drug Evaluation and Research (CDER). US FDA characterized ODT tablets as "A strong measurements structure containing restorative substances which crumbles quickly as a rule inside merely seconds, when set upon the tongue". European pharmacopoeia also adopted the term Orally disintegrating tablet as a tablet that is to be placed in the mouth where it disperses, rapidly before swallowing despite various terminologies used. Recently, ODT have started gaining popularity and acceptance as new drug delivery systems, because they are easy to administer and lead to better patient compliance especially in elderly and children. So as to enable quick dissolving tablets to break down in the mouth, they are made of either extremely permeable or delicate formed networks or compacted into tablets with low pressure power, which makes the tablets friable and additionally fragile, which are hard to deal with, regularly requiring specific strip off rankle bundling ${ }^{3-6}$.

Along with the rapid market growth of ODT products, the technologies, too, have advanced considerably over the years. The most up to date age of ODTs can deliver 
progressively strong, adaptable tablets that defeat a portion of the constraints of prior ODTs. Companies such as Eurand can produce pleasant tasting tablets, overcoming the common problem of poor drug taste compromising the benefits of an ODT. In addition, some companies is developing controlled release ODTs, significantly broadening the applications of this dosage form. A key reason that companies choose an ODT over other delivery technologies is that it is a relatively easy and often less risky delivery option to develop. Since the route of administration remains the same, ODTs that are formulated as bioequivalent line extensions or generic versions of an existing oral dosage form have minimal clinical requirements to gain approval ${ }^{7}$.

\section{MATERIALS AND METHODS}

\section{Materials}

Cetrizine hydrochloride was gift sample from Aurobindo Pharma., Hyderabad,India. Sodium starch glycolate, Croscarmellous sodium were purchased from Nihal traders Hyderabad, India. Magnesium stearate, Colloidal silicon dioxide, Lactose monohydrate were purchased from Span Pharma Private Limited Hyderabad, India. All other reagents used were of analytical grade.

\section{Methods}

Mouth fast dissolving tablets (MFDT's) were set up by direct pressure strategy as indicated by recipe given in Table 1 . All the ingredients were passed through mesh \# 30 except magnesium stearate ${ }^{8}$. Magnesium stearate was passed through mesh \# 40. Drug, and superdisintegrant were mixed by taking small portion of each in ascending order and blended to get a uniform mixture in a mortar. The other ingredients were weighed and mixed in geometrical order and tablets were compressed using $7 \mathrm{~mm}$ round flat punches on a Cadmach single punch machine.

\section{Manufacturing steps for direct compression method}

Direct compression involves comparatively few steps:

- Milling of drug and excipients.

- Mixing of drug and excipients.

- Tablet compression.

All the materials i.e., drug, Lactose monohydrate, colloidal silicon dioxide, superdisintegrating agents were sifted through mesh no.40 and were collected in mortar and mixed well to get a uniform mixture ${ }^{9}$. Magnesium stearate was sifted through mesh no.60 sieve, collected into the mortar containing other ingredients and mixed (added lastly as it is hydrophobic may affect dissolution and disintegration profile due to more time of mixing). The lubricated directly compressible blend was compressed by using direct compression machine to get hardness above $2.5 \mathrm{~kg} / \mathrm{cm}^{2}$. The tablets were sublimed at 40-50 $0 \mathrm{C}$ in a vacuum stove for 24 hours to brilliant subliming agent. End purpose of procedure is shown by complete expulsion of subliming specialist by sublimation ${ }^{10-12}$.

Table 1: Formula of Cetrizine hcl ODTs prepared by direct compression

\begin{tabular}{|c|c|c|c|c|c|c|c|c|c|c|c|c|c|c|c|}
\hline $\begin{array}{l}\text { Ingredients } \\
\text { (mg) }\end{array}$ & F1 & F2 & F3 & F4 & F5 & F6 & F7 & F8 & F9 & F10 & F11 & F12 & F13 & F14 & F15 \\
\hline $\begin{array}{l}\text { Cetrizine } \\
\text { hydrochloride }\end{array}$ & 10 & 10 & 10 & 10 & 10 & 10 & 10 & 10 & 10 & 10 & 10 & 10 & 10 & 10 & 10 \\
\hline Lactose & 2.2 & 2.2 & 2.2 & 2.2 & 2.2 & 2.2 & 2.2 & 2.2 & 2.2 & 2.2 & 2.2 & 2.2 & 2.2 & 2.2 & 2.2 \\
\hline Disintegrant & $\begin{array}{l}2 \% \\
\text { SSG }\end{array}$ & $\begin{array}{l}4 \% \\
\text { SSG }\end{array}$ & $\begin{array}{l}6 \% \\
\text { SSG }\end{array}$ & $\begin{array}{l}2 \% \\
\text { CCS }\end{array}$ & $\begin{array}{l}4 \% \\
\text { CCS }\end{array}$ & $\begin{array}{l}6 \% \\
\text { CCS }\end{array}$ & $\begin{array}{l}2 \% \\
\text { SSG } \\
+ \\
\text { CCS }\end{array}$ & $\begin{array}{l}4 \% \\
\text { SSG } \\
+ \\
\text { CCS }\end{array}$ & $\begin{array}{l}6 \% \\
\text { SSG } \\
+ \\
\text { CCS }\end{array}$ & $\begin{array}{l}2 \% \\
\text { SSG } \\
+ \\
\text { CCS }\end{array}$ & $\begin{array}{l}4 \% \\
\text { SSG } \\
+ \\
\text { CCS }\end{array}$ & $\begin{array}{l}6 \% \\
\text { SSG } \\
+ \\
\text { CCS }\end{array}$ & $\begin{array}{l}2 \% \\
\text { SSG } \\
+ \\
\text { CCS }\end{array}$ & $\begin{array}{l}4 \% \\
\text { SSG } \\
+ \\
\text { CCS }\end{array}$ & $\begin{array}{l}6 \% \\
\text { SSG } \\
+ \\
\text { CCS }\end{array}$ \\
\hline $\begin{array}{l}\text { Colloidal } \\
\text { silicondioxide }\end{array}$ & .052 & .052 & .052 & .052 & .052 & .052 & .052 & .052 & .052 & .052 & .052 & .052 & .052 & .052 & .052 \\
\hline $\begin{array}{l}\text { Magnesium } \\
\text { stearate }\end{array}$ & .052 & .052 & .052 & .052 & .052 & .052 & .052 & .052 & .052 & .052 & .052 & .052 & .052 & .052 & .052 \\
\hline
\end{tabular}

\section{CHARACTERIZATION OF TABLETS:}

Pre-compression Parameters ${ }^{13-15}$

\section{Angle of $\operatorname{Repose}(\theta)$ :}

A funnel was filled to the brim, allowing the test sample to flow smoothly under gravity through the orifice. The measurement of the stack region was taken from the cone created on the chart sheet, thus assessing the flow ability of the granules. The pile's height was also measured.

$\operatorname{Tan} \theta=\mathrm{h} / \mathrm{r}$

Where $\theta$ is the angle of repose

\section{Bulk Density:}

There was a determination of both loose bulk density (LBD) and tapped bulk density (TBD). An appropriate quantity of powder from each formulation was brought into a $10 \mathrm{ml}$ measuring cylinder, earlier slightly shaken to break agglomerates formed. After the initial volume was observed, the cylinder was allowed to fall from a height of $2.5 \mathrm{~cm}$ at intervals of 2 seconds under its own weight onto a hard surface.LBD and TBD were calculated using following formula.

$\mathrm{LBD}=$ weight of the powder/ volume of the packing

$\mathrm{TBD}=$ weight of the powder/tapped volume of the packing 


\section{Carr's compressibility Index}

Compressibility index of the powder was determined by Carr's compressibility index.

Carr's index $(\%)=[(\mathrm{TBD}-\mathrm{LBD}) \mathrm{X} 100] / \mathrm{TBD}$

Post-compression Parameters ${ }^{16-18}$ :

\section{Uniformity of weight:}

The experiment was performed by the Indian pharmacopoeia. Twenty tablets were weighed separately from each formulation and the tablet weight average was calculated. The percentage weight variation compared to the mean tablet weight was calculated separately

\section{Hardness:}

The fracture strength, which is defined as the force required to break a tablet by radial compression, was measured with a tablet hardness tester (Monsanto hardness tester) $(n=3)$.

\section{Friability:}

A tablet's pharmacopoeial friability test threshold is not more than 1 percent using Tablet friability device, performed for 4 minutes at $25 \mathrm{rpm}$ (100 rotations). This test again does not apply to lyophilized and flash dose tablets, but is always suggested for tablets prepared using direct compression and moulding methods to guarantee sufficient mechanical strength.

Percentage friability $=100$ (initial weight-final weight)/initial weight $($ Or $) \%$ Friability $=($ Loss in weight $/$ Initial weight $) \times$ 100

\section{Wetting time:}

In a tiny Petri dish containing $6 \mathrm{ml}$ of phosphate buffer $\mathrm{pH}$ 6.8 , a piece of tissue paper folded twice was put. A tablet was placed on the paper and measured the time required for full wetting $(\mathrm{n}=3)$.).

\section{Water absorption ratio:}

The water absorption ratios of the tablet were carried out in petri dishes with $\mathrm{pH} 6.8$ phosphate buffer.Peroidically,the tablets were withdrawn from the petri dishes and weighed on electronic balance after removal of surface water by light blotting with a lab tissue for change of their weight till a constant weight is attained.

In vitro dispersion time ${ }^{19}$ :

In vitro dispersion time was measured by using $10 \mathrm{ml}$ of phosphate buffer $\mathrm{pH} 6.8$ in $25 \mathrm{ml}$ beaker at $37 \pm 0.5{ }^{\circ} \mathrm{C}$ temperature. Time required for dispersion of the tablets was noted. In each formulation three tablets were tested $(n=3)$.

In vitro dissolution study ${ }^{20}$ :

ODTs have been assessed for conduct of dissolution. Dissolution testing was performed using USP device 2, type of paddle. Dissolution was performed at $50 \mathrm{rpm}$ rotational speed using $900 \mathrm{ml}$ of phosphate buffer $\mathrm{pH} 6.8$ as the dissolution medium maintained at $37 \pm 0.5^{\circ} \mathrm{C}$. Samples were removed at a predetermined interval of time, diluted appropriately and analyzed for cumulative drug at $231 \mathrm{~nm}$.

\section{RESULTS \& DISCUSSION:}

\section{Results of pre-compression parameters for Cetrizine hydrochloride tablet}

\section{Angle of repose $(\theta)$ :}

The data obtained from the repose angle for all formulations were found to be within the range of $24.19^{\circ}$ and $28.56^{\circ}$ which shows excellent flow properties. All formulations with a rest angle of $30^{\circ}$ indicate a decent flow property of the granules.

\section{Bulk density:}

Bulk density (BD) was done for the mix and tapped density (TD). The loose bulk density and tapped bulk density ranged from $0.508 \mathrm{gm} / \mathrm{cc}$ to $0.5438 \mathrm{gm} / \mathrm{cc}$ and 0.5941 to 0.6408 respectively for the complete formulation mix.

\section{Carr's compressibility index:}

The findings for the entire formulation mix of Carr's consolidation index or compressibility index (percent) ranged from 14.30 percent to 17.53 percent showed outstanding compressibility index values of up to 15 percent, resulting in good to outstanding flow properties. As shown in the job of prior studies. Tabulate all the outcomes in Table 2.

Table 2: Results of pre-compression parameters for Cetrizine hydrochloride tablet

\begin{tabular}{|c|c|c|c|c|}
\hline Formulation code & Bulk density g/cc & Tapped density (g/cc) & Angle of repose & Carr's index(\%) \\
\hline F1 & $0.543 \pm 0.01$ & $0.63 \pm 0.03$ & $25.28 \pm 0.02$ & $14.30 \pm 0.05$ \\
\hline F2 & $0.52 \pm 0.02$ & $0.62 \pm 0.05$ & $27.20 \pm 0.04$ & $17.19 \pm 0.01$ \\
\hline F3 & $0.59 \pm 0.04$ & $0.60 \pm 0.01$ & $25.14 \pm 0.08$ & $15.75 \pm 0.02$ \\
\hline F4 & $0.50 \pm 0.01$ & $0.59 \pm 0.06$ & $24.19 \pm 0.02$ & $15.00 \pm 0.06$ \\
\hline F6 & $0.54 \pm 0.05$ & $0.64 \pm 0.02$ & $26.41 \pm 0.01$ & $15.04 \pm 0.03$ \\
\hline F7 & $0.53 \pm 0.03$ & $0.62 \pm 0.01$ & $28.56 \pm 0.07$ & $17.71 \pm 0.04$ \\
\hline F8 & $0.51 \pm 0.04$ & $0.62 \pm 0.03$ & $26.38 \pm 0.09$ & $16.63 \pm 0.04$ \\
\hline F10 & $0.53 \pm 0.08$ & $0.64 \pm 0.02$ & $26.01 \pm 0.02$ & $14.35 \pm 0.04$ \\
\hline F11 & $0.50 \pm 0.05$ & $0.59 \pm 0.06$ & $27.01 \pm 0.06$ & $14.34 \pm 0.02$ \\
\hline F12 & $0.53 \pm 0.06$ & $0.58 \pm 0.04$ & $26.98 \pm 0.04$ & $15.98 \pm 0.01$ \\
\hline F13 & $0.50 \pm 0.03$ & $0.56 \pm 0.05$ & $26.87 \pm 0.07$ & 27.07 \\
\hline F15 & $0.54 \pm 0.01$ & $0.54 \pm 0.08$ & $27.82 \pm 0.01$ & 16.03 \\
\hline
\end{tabular}


Results of post-compression parameters for Cetrizine hydrochloride tablet

\section{Hardness:}

All tablets were preserved in hardness from $2.00 \mathrm{~kg} / \mathrm{cm}$ to $4.00 \mathrm{~kg} / \mathrm{cm}$. Tabulate the mean outcomes of the hardness test in Table 3.

\section{Friability test:}

Friability was discovered to be well within the authorized range $(<1 \%)$ in all constructed formulations in the range 0.42 to $0.74 \%$. The findings of the friability research were summarized in Table 3.

\section{Weight variation test:}

The weight variation was discovered in the range of 97 to $102 \mathrm{mg}$ in all constructed formulations. Tabulate the mean weight variation test outcomes in table 3.All tablets passed weight variation test as the average weight variation was within 7.5 percent i.e. the pharmacopie limits.

\section{In-vitro disintegration time:}

The time taken to undergo standardized disintegration is evaluated in vitro. Rapid disintegration was noted in all formulations within several minutes. Cetrizine Hcl's in vitro disintegration moment, prepared by super disintegrate using a direct compression technique, was discovered to be between 18 and 11 seconds in line with official requirements.

Based on the in vitro disintegration time, formulation F12and F15 were found to be promising and showed a disintegration time of 18 and $11 \mathrm{sec}$ respectively.

Disintegrating study showed that the disintegrating times of the tablets decreased with combination of both sodium starch glycolate and cross carmellose with different concentrations. It also showed least disintegration time in comparison with the all other formulation because of their lowest hardness and the porous structure is responsible for faster water uptake, hence it facilitates swelling action in bringing about fast disintegration.

\section{Wetting time:}

Wetting time closely related to the inner structure of the tablet. The results of wetting time are shown in table. The wetting time were found to be in the range of 11 to $18 \mathrm{sec}$.

Water absorption ratio: Water absorption ratio for all the formulations found in the range 11 to $16 \%$. The results of water absorption ratio for tablets were shown in Table 3.

Table 3: Results of post compression parameters for Cetrizine hydrochloride tablet

\begin{tabular}{|c|c|c|c|c|c|c|c|}
\hline $\begin{array}{l}\text { Formulation } \\
\text { code }\end{array}$ & Hardness & Friability & Thickness & Weight variation & $\begin{array}{l}\text { In-vitro dispersion } \\
\text { time(sec) }\end{array}$ & $\begin{array}{l}\text { Wetting } \\
\text { time(sec) }\end{array}$ & Water absorption (\%) \\
\hline F1 & $3.5 \pm 0.4$ & 0.69 & 3.21 & $100 \pm 1.5$ & $32 \pm 2$ & $27 \pm 3$ & $13 \pm 2$ \\
\hline F2 & $3.5 \pm 0.2$ & 0.46 & 3.30 & $99 \pm 2.0$ & $28 \pm 6$ & $25 \pm 4$ & $17 \pm 4$ \\
\hline F3 & $3.9 \pm 0.1$ & 0.72 & 3.12 & $101 \pm 0.8$ & $26 \pm 8$ & $18 \pm 5$ & $18 \pm 3$ \\
\hline F4 & $3.8 \pm 0.2$ & 0.72 & 3.29 & $102 \pm 0.5$ & $50 \pm 4$ & $33 \pm 2$ & $13 \pm 1$ \\
\hline F5 & $3.6 \pm 0.3$ & 0.68 & 3.34 & $99 \pm 1.2$ & $40 \pm 3$ & $25 \pm 1$ & $16 \pm 6$ \\
\hline F6 & $3 . .5 \pm 0.4$ & 0.43 & 3.36 & $98 \pm 1.8$ & $30 \pm 2$ & $21 \pm 6$ & $15 \pm 4$ \\
\hline F7 & $4.0 \pm 0.0$ & 0.42 & 3.29 & $99 \pm 1.0$ & $30 \pm 8$ & $29 \pm 4$ & $14 \pm 3$ \\
\hline F8 & $3.8 \pm 0.1$ & 0.45 & 3.36 & $97 \pm 1.8$ & $26 \pm 7$ & $26 \pm 3$ & $14 \pm 1$ \\
\hline F9 & $3.7 \pm 0.2$ & 0.54 & 3.30 & $100 \pm 0.5$ & $20 \pm 5$ & $20 \pm 5$ & $13 \pm 5$ \\
\hline F10 & $3.9 \pm 0.1$ & 0.57 & 3.21 & $98 \pm 1.2$ & $26 \pm 6$ & $26 \pm 4$ & $14 \pm 4$ \\
\hline F11 & $3.8 \pm 0.2$ & 0.53 & 3.33 & $100 \pm 0.2$ & $24 \pm 1$ & $24 \pm 2$ & $13 \pm 2$ \\
\hline F12 & $3.7 \pm 0.3$ & 0.41 & 3.12 & $101 \pm 0.5$ & $18 \pm 2$ & $23 \pm 1$ & $12 \pm 3$ \\
\hline F13 & $3.5 \pm 0.4$ & 0.52 & 3.42 & $99 \pm 1.2$ & $23 \pm 5$ & $20 \pm 3$ & $13 \pm 1$ \\
\hline F14 & $3.3 \pm 0.6$ & 0.40 & 3.32 & $100 \pm 0.2$ & $19 \pm 4$ & $15 \pm 6$ & $12 \pm 2$ \\
\hline F1 & $3.5 \pm 0.4$ & 0.69 & 3.21 & $100 \pm 1.5$ & $32 \pm 2$ & $27 \pm 3$ & $13 \pm 2$ \\
\hline
\end{tabular}

\section{DISSOLUTION STUDY}

\section{In vitro dissolution studies:}

Dissolution rate was studied by using USP type-2 apparatus using $900 \mathrm{ml}$ of phosphate buffer $\mathrm{pH}$ (6.8) as dissolution medium. Temperature of the dissolution medium was maintained at $37 \pm 0.5^{\circ} \mathrm{c}$, aliquot of dissolution medium withdrawn at every $15 \mathrm{sec}$ interval and filtered. The absorbance of the filtered solution was measured by UV spectrophotometric method at $231 \mathrm{~nm}$ and concentration of the drug was determined from the standard calibration curve.The dissolution profile of Cetrizine hydrochloride from the tablets is shown in the Table no: 4 and comparative release profiles were shown in the Figures 1-3.

Table 4: Cumulative Percentage Drug Release Profiles

\begin{tabular}{|c|c|c|c|c|c|c|c|c|c|c|c|c|c|c|c|}
\hline $\begin{array}{l}\text { Time } \\
\text { (Sec) }\end{array}$ & F1 & F2 & F3 & F4 & F5 & F6 & F7 & F8 & F9 & F10 & F11 & F12 & F13 & F14 & F15 \\
\hline 15 & 32.7 & 40.7 & 41.7 & 34.3 & 35.5 & 36.3 & 29.5 & 31.4 & 36 & 29 & 33.7 & 30 & 33.4 & 36.6 & 47.6 \\
\hline 30 & 36.8 & 43.3 & 43.7 & 38.8 & 39.7 & 43 & 34.7 & 38.7 & 40.8 & 34 & 38.5 & 38.7 & 36.6 & 44.3 & 56.4 \\
\hline 45 & 43.1 & 47.8 & 48.1 & 4.19 & 44.4 & 49.7 & 36 & 42.3 & 44.7 & 38.8 & 40.4 & 44.4 & 41.8 & 51.4 & 64.8 \\
\hline 60 & 56.6 & 57.4 & 58.4 & 44 & 50.1 & 59.4 & 40.4 & 48.2 & 58.8 & 42 & 45 & 60.6 & 42.5 & 54.7 & 70.6 \\
\hline 75 & 61 & 65.8 & 68.8 & 50 & 57 & 67.6 & 44.7 & 55.7 & 62.8 & 46.4 & 53.5 & 66.3 & 48.3 & 53.9 & 75.7 \\
\hline 90 & 65.9 & 66.4 & 69.3 & 60.7 & 62.5 & 70.9 & 49 & 65.5 & 67.7 & 51.5 & 67 & 70.2 & 51.9 & 66.5 & 81 \\
\hline
\end{tabular}




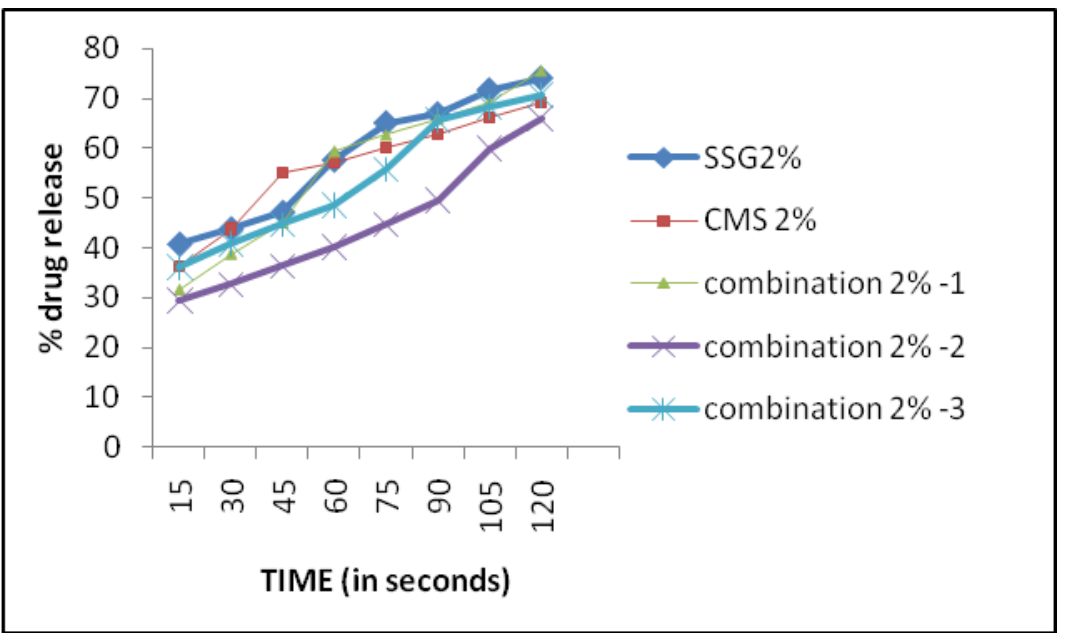

Figure 1: Release profile of formulations F1, F4, F7, F10, F13

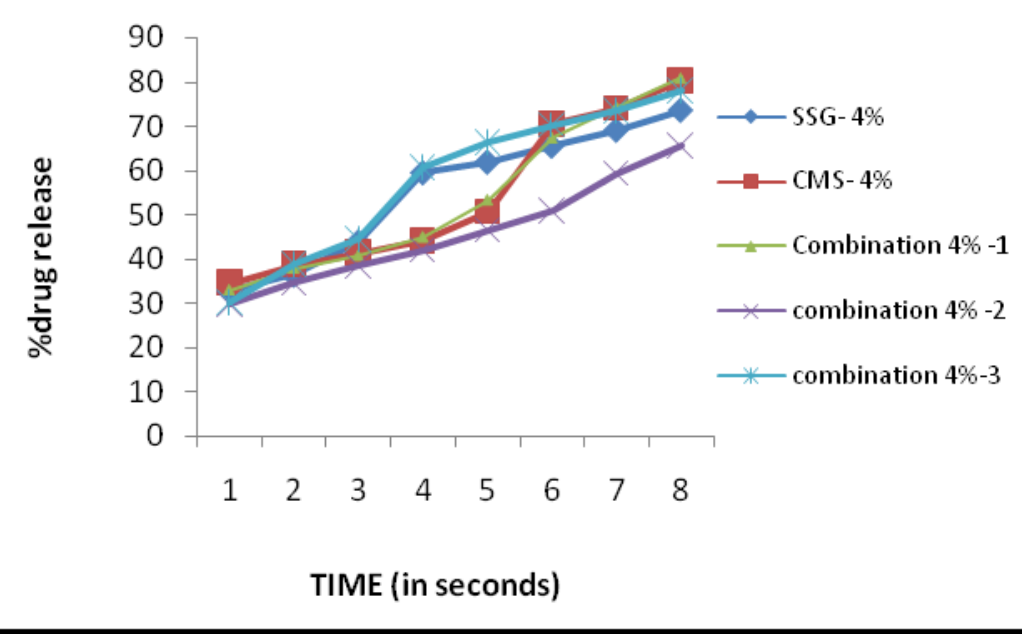

Figure 2: Release profile of formulations F2, F5, F8, F11, F14

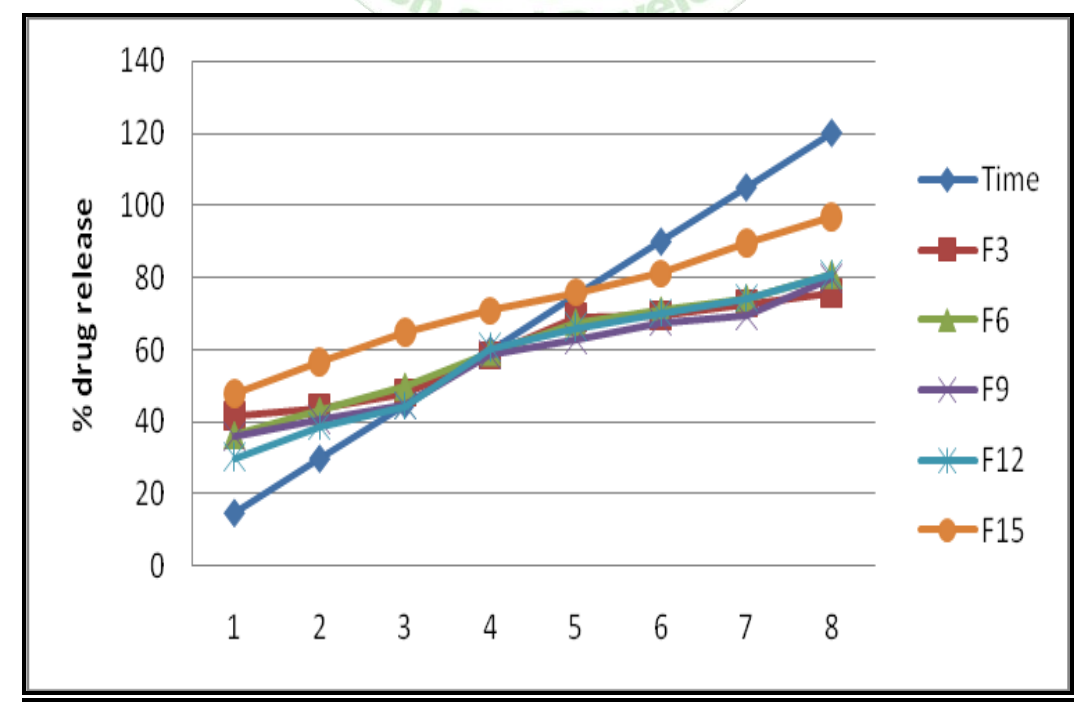

Figure 3: Release profile of formulations F3, F6, F9, F12, F15

\section{CONCLUSION}

Dissolution rate of tablets with CCS and SSG improves when concentration increased from $2 \%$ to $4 \%$ and $4 \%$ to $6 \%$. Dissolution rate of tablets with SSG was significantly less when compared to the tablets with CCS at initial time points. From the above results of the study it can be concluded that combination of sodium starch glycolate and crosscarmellose sodium (6\% of $25 \%$ SSG \& $75 \%$ CCS) could be the alternative approach to increase the dissolution of tablets 
when compared to the formula with sodium starch glycolate and crosscarmellose alone as disintegrate. Hence the combination of sodium starch glycolate and crosscarmellose sodium ( $6 \%$ of $25 \%$ SSG \& $75 \%$ CCS) promotes dissolution rate of drug release when compared to formulation of SSG \& CCS alone .It may be due to capillary and wicking mechanism of SSG \& CCS.

\section{REFERENCES}

1. Sreenivas SA. Orodispersible tablets: New- fangled drug delivery system- A Review. IndianJ.Pharm.Educ.Res 2005; 39(4):177-81.

2. Chein YW. Oral Drug Delivery and Delivery systems, 2nd ed., New York: Marcel Dekker, 1992.

3. Rakesh RK. Orally Disintegrating Tablets novel tablets novel approach to drug delivery. Pharma Review 2004; 2(12):34- 36

4. Kuchekar BS, Badhan AC, Mahajan HS. Mouth dissolving tablets: a novel drug delivery system. Pharma Times 2003; 35:1-8

5. Brown D. Orally disintegrating tablets-taste over speed. Drug Delivery Technology 2003; 3(6):58-61.

6. Klauke J. Dissolution testing of orally disintegrating tablets. Dissolution Technologies| 2003; (1):6-8.

7. Harmon TM. Beyond the First Generation of Orally Disintegrating Tablets. Emerging Technology. Tablets and Capsules.2006; 9(3).

8. Jashanjit Singh,1 Anil K. Philip,1 and Kamla Pathak Optimization Studies on Design and Evaluation of Orodispersible Pediatric Formulation of Indomethacin AAPS Pharm Sci Tech.2008; 9(1).

9. Gohel M. Tablet Disintegrants. Pharmainfo. 2013.

10. R. F. Shangraw, Vol. 4, 2nd Ed., Marcel Dekker, Newyork USA, p. 85, 1988.

11. M. Jivraj, L. G. Martini and C. M. Thomson, PSTT.2008; 3-58.

12. Gohel MC, Jogani PD, A review of co-processed directly compressible excipients. J Pharm Sci. 2005; 8(1):76-93.

\section{ACKNOWLEDGMENTS}

The authors would like to thank the Management of Bharat Institute of Technology, Mangalpally (V), Ibrahimpatnam (M), R.R-Dist. for providing facilities to evaluate the formulations.
13. Leon Lachman, Herbert Liberman, Joseph L. Kanig, in: Theory and Practice of Industrial Pharmacy, 2nd Edn. Varghese Publication, 1985.

14. Herbert A. Lieberman, Leon lachman and Joseph B. Schwartz; Pharmaceutical Dosage forms; Tablet, Vol. - I $2^{\text {nd }}$.

15. Raymond C Rowe, Paul J Sheskey and Marian E Quinn; Handbook of Pharmaceutical excipients. 6 edition.

16. Battu SK, Repka MA, Majumdar S, Rao MY. Formulation and evaluation of rapidly disintegrating tablet Fenoverine tablets: Effect of superdisintegrants. Drug Dev Ind Pharm. 2007; 33:1225-32.

17. Gohel M, Patel M, Amin A, Agrawal R, Dave R, Bariya N. Formulation design and optimization of mouth dissolve tablets of nimesulide using vacuum drying technique. AAPS Pharm Sci Tech. 2004; 5 :e36.

18. Bi Y, Sunada H, Yonezawa Y, Danjo K, Otsuka A, Iida K Preparation and evaluation of a compressed tablet rapidly disintegrating in the oral cavity. Chem Pharmaceut Bull (Tokyo). 1996; 44:2121-7.

19. El-Arini SK, Clas SD. Evaluation of disintegration testing of different fast dissolving tablets using texture analyzer. Pharm Dev Technol, 2002; 7(3):361-371.

20. Klancke J. Dissolution testing of orally disintegrating tablets. Dissolution Technol, 2003; 10(2):6-8. 